Dismiss this thought, or accept it, Sulmasy certainly makes us examine ourselves, and what we do, and how we do it, and keeps the spiritual dimension of health care a live issue!

THE REV J RONALD DICK

Hospital Chaplain, Borders General Hospital Melrose, Roxburghshire TD6 9BS

\section{The Health Care Ethics Committee Experience}

Edited by Stuart F Spicker, Malabar, Kreiger Publishing Company, 1998, 452 pages, US\$ $\$ 9.50$.

This book comprises a selection of papers originally published in the journal Healthcare Ethics Committee Forum (HEC Forum). Its stated aim is to provide a coherent introduction to the everyday work and problems faced by healthcare ethics committees (HECs). With the emergence of a small number of hospital ethics committees in the UK and Europe, and the likelihood of more developing, this publication is timely. The book is divided into ten sections although issues tend to overlap between sections. The initial sections focus on general considerations in setting up a committee and differing visions of HECs. The concept of the healing dimension of an HEC in providing a forum for dialogue and mutual respect together with an ability to articulate moral values, thus allowing resolution of ethical conflict, is specifically addressed here but is a recurring theme throughout the book. A paper by Sichel argues that the ethics of care espoused by Gilligan and Noddings may be a better basis for HEC deliberations than the traditional ethical theories of rights and justice. Cushman argues that the HEC's role is to ensure that clinical decision making is congruent with generally accepted bioethical principles, offering a more formulaic approach than that suggested by the other writers in this section. Blake proposes that the hospital should be viewed as a moral community with the HEC being responsible for "exploring and articulating those boundaries of conduct that define the moral character of the hospital".

The education and case review functions of HECs are considered in separate sections. Papers in the education section focus on the role of HECs in self-education for committee members and education of hospital staff. A role for the committee in education of the wider community is also considered. Practical suggestions for developing education programmes based on the experiences of several HECs are offered. Rawlins and Bradley present their findings of a clear difference between physicians and nurses in their perceptions of an HEC's role and their preferred method of ethics education, an important, if not entirely surprising, factor that will need to be addressed by any HEC education strategy. Case review by HECs is allotted two sections. Is this a reflection of its perceived importance? Ross argues that by using a committee to review ethically difficult cases the hospital communicates its commitment to the creation of an ethical community. Loewy suggests a role for both ethics committee and ethics consultant in case reviews, illustrated by his personal experience as an ethics consultant and member of an ethics committee. Glaser and Miller suggest that the goal of HECs should be to enable all professionals in the hospital to shoulder their ethical responsibilities and resolve ethical dilemmas by effective case conferencing. Case review by the committee would then be used to influence policy development and not to resolve individual cases. A number of issues pertinent to case review by HECs are discussed, including the role of patients and family members and whether a committee should make binding decisions.

Individual members of HECs discuss their roles in one section. The comments of the community member on the frustration of dealing with the effect of institutional dynamics on implementation of HEC policy guidelines are illuminating. The legal aspects of HECs are considered. A discussion on whether HECs should ever provide advice contrary to the law is in the form of two papers, one arguing for and one arguing against the motion, a format which is used effectively in several sections of the book.

The later sections consider the extension of the HEC's role into new areas such as hospital administration, long term care facilities and the community. Should HECs consider the ethics of business decisions taken by the hospital managers or contribute to management policy? Other models of addressing the issue of ethical concerns in the administration of the hospital are considered, including devel- oping a separate corporate ethics committee. How are HECs developing outside hospitals? Alternative models for the structure and functioning of HECs in different environments are considered. Meece describes a cooperative model which draws members from all long term care institutions in Sonoma County, California and which has been able to develop guidelines on "Do Not Resuscitate" orders and informed consent which have been implemented across the county. Wilson describes a community bioethics committee which is separate from health care institutions and open to all citizens for support and information on bioethics issues.

The final section looks to the future. The effect on HEC deliberations of the need for cost containment in health care is considered, with the suggestion that this will entail a shift in priority from the principle of autonomy to that of justice. The possible role of HECs in setting legally recognised standards of medical practice and influencing legislation is also raised.

This collection of papers provides a thought-provoking and useful overview of the development of HECs in the US. Many of the authors use examples of cases to illustrate their argument, which adds interest. Only one paper mentions the need for evaluation of HECs and there is no debate on the intrinsic value of HECs. Some of the discussion may not be relevant to readers outside the US but I would recommend this book as essential reading for anyone considering setting up a healthcare ethics committee and for those interested in the practicalities of incorporating theoretical medical ethics into clinical care.

ANNE SLOWTHER General Practitioner, Gloucestershire

\section{Ethics, Computing and Medicine: Informatics and the Transformation of Health Care}

Edited by Kenneth W Goodman, Cambridge, Cambridge University Press, 1998,180 pages, $£ 15.95$ (sc) (US\$24.95), £45.00 (hb)

(US\$64.95).

This collection of eight articles, the majority of which are published here 